\title{
Co-production of GroELS discriminates between intrinsic and thermally-induced recombinant protein aggregation during substrate quality control
}

Gemma Platas ${ }^{1,2,3+}$, Escarlata Rodríguez-Carmona ${ }^{1,2,3+}$, Elena García-Fruitós ${ }^{3,1+}$, Olivia Cano-Garrido ${ }^{1,2,3}$ and Antonio Villaverde $e^{1,2,3^{*}}$

\begin{abstract}
Background: The effects and effectiveness of the chaperone pair GroELS on the yield and quality of recombinant polypeptides produced in Escherichia coli are matter of controversy, as the reported activities of this complex are not always consistent and eventually indicate undesired side effects. The divergence in the reported data could be due, at least partially, to different experimental conditions in independent research approaches.

Results: We have then selected two structurally different model proteins (namely GFP and E. coli $\beta$-galactosidase) and two derived aggregation-prone fusions to explore, in a systematic way, the eventual effects of GroELS coproduction on yield, solubility and conformational quality. Host cells were cultured at two alternative temperatures below the threshold at which thermal stress is expected to be triggered, to minimize the involvement of independent stress factors.

Conclusions: From the analysis of protein yield, solubility and biological activity of the four model proteins produced alone or along the chaperones, we conclude that GroELS impacts on yield and quality of aggregationprone proteins with intrinsic determinants but not on thermally induced protein aggregation. No effective modifications of protein solubility have been observed, but significant stabilization of small (encapsulable) substrates and moderate chaperone-induced degradation of larger (excluded) polypeptides. These findings indicate that the activities of this chaperone pair in the context of actively producing recombinant bacteria discriminate between intrinsic and thermally-induced protein aggregation, and that the side effects of GroELS overproduction might be determined by substrate size.
\end{abstract}

\section{Introduction}

Recombinant protein production is a leading methodological platform of biotechnology and biomedicine [1]. Protein misfolding, degradation, aggregation, inclusion body formation and low functional protein quality are among the main obstacles encountered when using conventional bacterial hosts such as Escherichia coli [2-4] as cell factories, these events being specially distressing when proteins are intended for therapeutic uses $[5,6]$.

\footnotetext{
* Correspondence: antoni.villaverde@uab.cat

† Contributed equally

'Institut de Biotecnologia i de Biomedicina, Universitat Autònoma de

Barcelona, Bellaterra, Barcelona, Spain

Full list of author information is available at the end of the article
}

Apart from shifting to a growing number of alternative hosts, what might eventually improve protein yield and quality, several strategies have been implemented to favour recombinant protein yield and quality in bacteria, specially addressed to enhance proteolytic stability and minimize aggregation [3,7]. As the activities of the cell's quality control were identified ([8], and references therein), the co-production of chaperones along with the target protein was taken as a routine approach. Firstly individual chaperones, and later chaperone-cochaperone pairs or larger chaperone sets, supplied from additional plasmid vectors, have been assayed as folding modulators under different experimental setting ups and for a large catalogue of proteins [9]. Despite reports of 
relevant successes, a consensus about final doses and composition of the best chaperone catalogue has not been reached, as the positive effects of this strategy seem to be highly dependent, among other potential factors, on the specific recombinant protein. In addition, externally supplied chaperones might show side effects on the whole physiology of recombinant cells and eventually compromise the quality, solubility or yield of the target recombinant protein $[10,11]$. Such undesired effects might limit the success of this method, and their occurrence can account, at least partially, for the lack of consistency of chaperone co-production as a generic strategy.

DnaK, a key negative regulator of the quality control system and the main cytosolic E. coli chaperone (acting together with its co-chaperone DnaJ) is a common component of the most successful chaperone sets $[9,12]$. However, an excess of DnaK is recognized to promote functional inactivation of the target protein and eventually its massive proteolysis, at least in given experimental setting ups [13-15]. Protein degradation mediated by DnaK seems to be mechanistically connected to the disaggregation process on the surface of inclusion bodies (where DnaK accumulates), in which by DnaK-DnaJ, IbpA-IbpB and ClpP participate [16]. DnaK-mediated degradation of recombinant polypeptides might represent a physiological replica of $\sigma^{32}$ inactivation, through its DnaK-mediated delivery to the protease La during the regulation of the heat shock circuits [17]. Recombinant protein production in DnaK knock out mutants, in contrast, results in high yields of recombinant protein and larger inclusion bodies [18].

The activities of GroEL, the other main cytosolic chaperone in $E$. coli, on recombinant protein solubility, but specially their potential side effects on protein quality are much less known. This might be due to the fact that GroEL knock out mutants are not viable [19], and that studies on partially inactivating groEL mutations [20] or truncated versions of the chaperone [21] might render non conclusive results. GroEL co-production has been shown to enhance solubility and/or yield of different proteins, at very different extents (although sometimes with no perceivable or very mild effects) and under different production conditions [22]. GroELS, apart from acting in the sequential folding steps of nascent polypeptides [23-26], is a holding chaperone that can also promote natural and recombinant protein stability and the formation of large macromolecular complexes such as tobacco mosaic virus-like particles [27] and fully assembled P22 phage virions [28], by preventing aggregation and proteolysis of thermolabile intermediates. However, the effects of these chaperones on recombinant protein yield and functional quality are extremely difficult to summarize since diverse authors focus on different analytical parameters, with alternative criteria and under diverse experimental conditions. Also, the potential contribution of thermally induced aggregation of intrinsically aggregation-prone proteins in GroELS activities has been essentially neglected. Beside these findings and considerations, independent observations have again suggested instability of target proteins as potential, undesired effects associated to GroEL overproduction [10], in special, proteolysis of proteins deposited as inclusion bodies [29].

\section{Results}

To examine in a defined experimental setting up, how GroEL and its co-chaperone GroES can affect the yield, stability and quality of aggregation-prone polypeptides, and to identify mechanistic roles of this chaperone pair in the quality control of recombinant proteins we have selected as models two structurally dissimilar soluble proteins (namely GFP and E. coli $\beta$-galactosidase). These polypeptides were produced as non-fused, pseudo wild type versions or joined to a hydrophobic viral protein (the VP1 capsid protein of foot-and-mouth disease virus) that acts as an efficient aggregation tag. While GFP is a monomeric small protein $(27 \mathrm{kDa})$ that gains activity through a maturation process in the last folding steps [30], $\beta$-galactosidase is a huge tetrameric protein $(470 \mathrm{kDa})$ that becomes active once the correct contacts between the monomer's interfaces have been stabilized [31]. Point mutations in GFP have a dramatic impact on the aggregation rate of the protein [32] while disposition of both GFP (and related fluorescent proteins) and $\beta$ galactosidase as inclusion bodies is also sensitive to the amino acid sequence and position of end-terminal fused aggregation tags [33-35]. Aggregation-prone versions of both proteins have been shown to interact in vivo with GroEL [36-38].

To minimize the contribution of thermal stress on protein deposition we tested recombinant protein production at two suboptimal growth temperatures, namely $16^{\circ} \mathrm{C}$ and $27^{\circ} \mathrm{C}$. The non-fused GFP was fully soluble when produced in $\mathrm{E}$. coli at $16^{\circ} \mathrm{C}$ (Figure 1A). However, around $40 \%$ of recombinant GFP occurred in the insoluble cell fraction when the culture temperature was upset to $27^{\circ} \mathrm{C}$ (Figure 1A). Co-production of GroELS did not improve GFP solubility in any of these production conditions (Figure 1A). Also, GFP yield was very similar in all cases, excluding the possibility of extended proteolysis mediated by the chaperones. In contrast, the aggregation-prone version of the same protein (VP1GFP) was mainly insoluble at both $16^{\circ} \mathrm{C}$ and $27^{\circ} \mathrm{C}$ (Figure $1 \mathrm{~B}$ ), indicating an intrinsic rather than environmentalinduced trend to deposition mediated by the viral tag. The yield of VP1GFP at $27^{\circ} \mathrm{C}$ was significantly lower than that at $16^{\circ} \mathrm{C}$, suggesting proteolysis of this protein. 

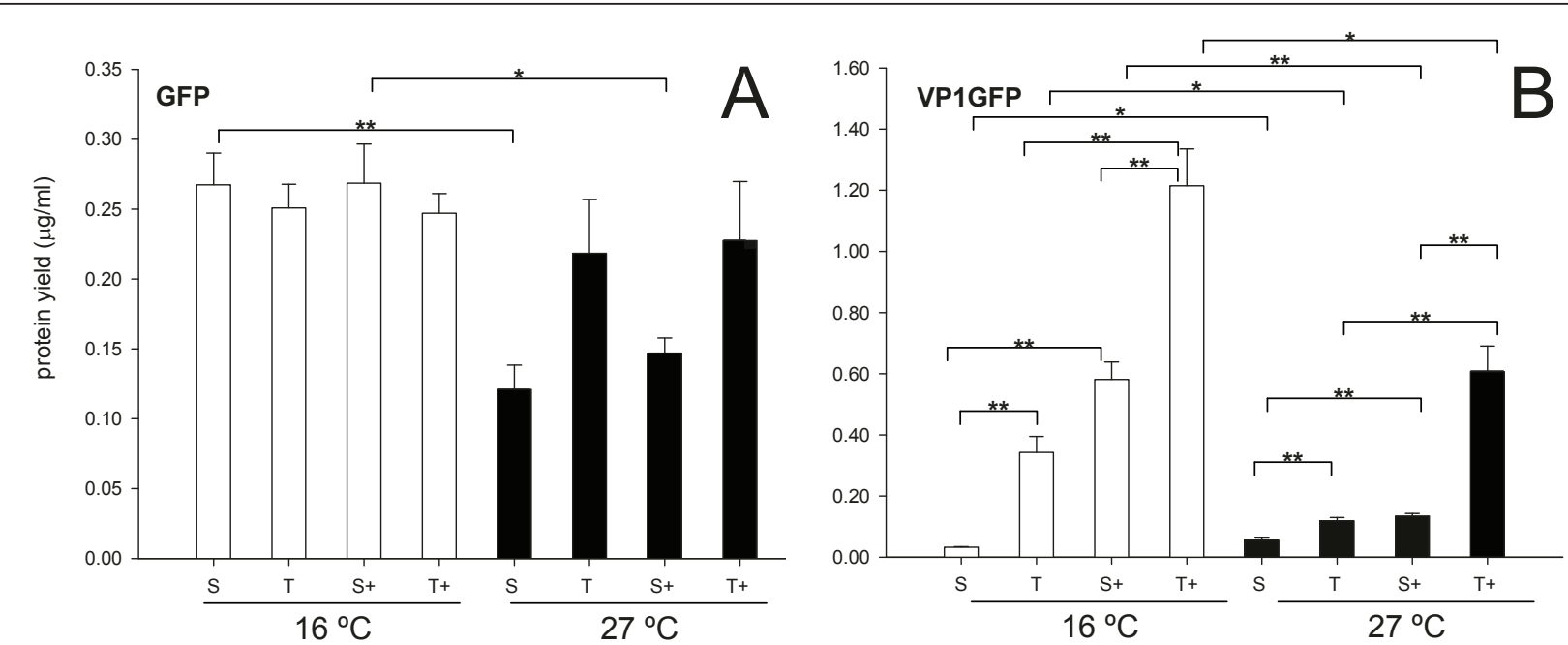

Figure 1 Influence of GroELS co-production on yield and solubility of native and engineered GFPs. Yield of total (T) and soluble (S) GFP (A) and VP1GFP (B) produced alone or along with the chaperones GroELS (+). Only significant differences between relevant data pairs are indicated as *, $0.01<p<0.05$ and ${ }^{* *} p<0.01$.

However, and in contrast with GFP, the co-production of GroELS dramatically enhanced the yield of VP1GFP (Figure 1B). Furthermore, VP1GFP solubility, expressed as the ratio of protein occurring in the soluble fraction over total protein, was not dramatically enhanced by the chaperones at $27^{\circ} \mathrm{C}$ (Figure $1 \mathrm{~B}$ ). The five-fold increase in solubility observed at $16^{\circ} \mathrm{C}$ might be a numerical rather than a factual issue linked to data scattering at low yield values.

When exploring GFP conformational and functional quality through the fluorescence emitted per mass ratio, higher conformational quality was immediately evidenced at $27^{\circ} \mathrm{C}$ (Figure 2A), indicative of a more efficient protein maturation. At this temperature, the soluble protein version was slightly more fluorescent than the aggregated counterparts, as expected. GroELS had no detectable effect on the fluorescence emission of GFP at any temperature (Figure 2A). A similar global profile was observed during the production of VP1GFP. However, in this case, the chaperone complex minimized the fluorescence emission of both soluble and aggregated versions of VP1GFP (Figure 2B), whose yield was enhanced by the chaperones.

$\beta$-Galactosidase was, as in the case of GFP, essentially soluble and both protein yield and solubility essentially

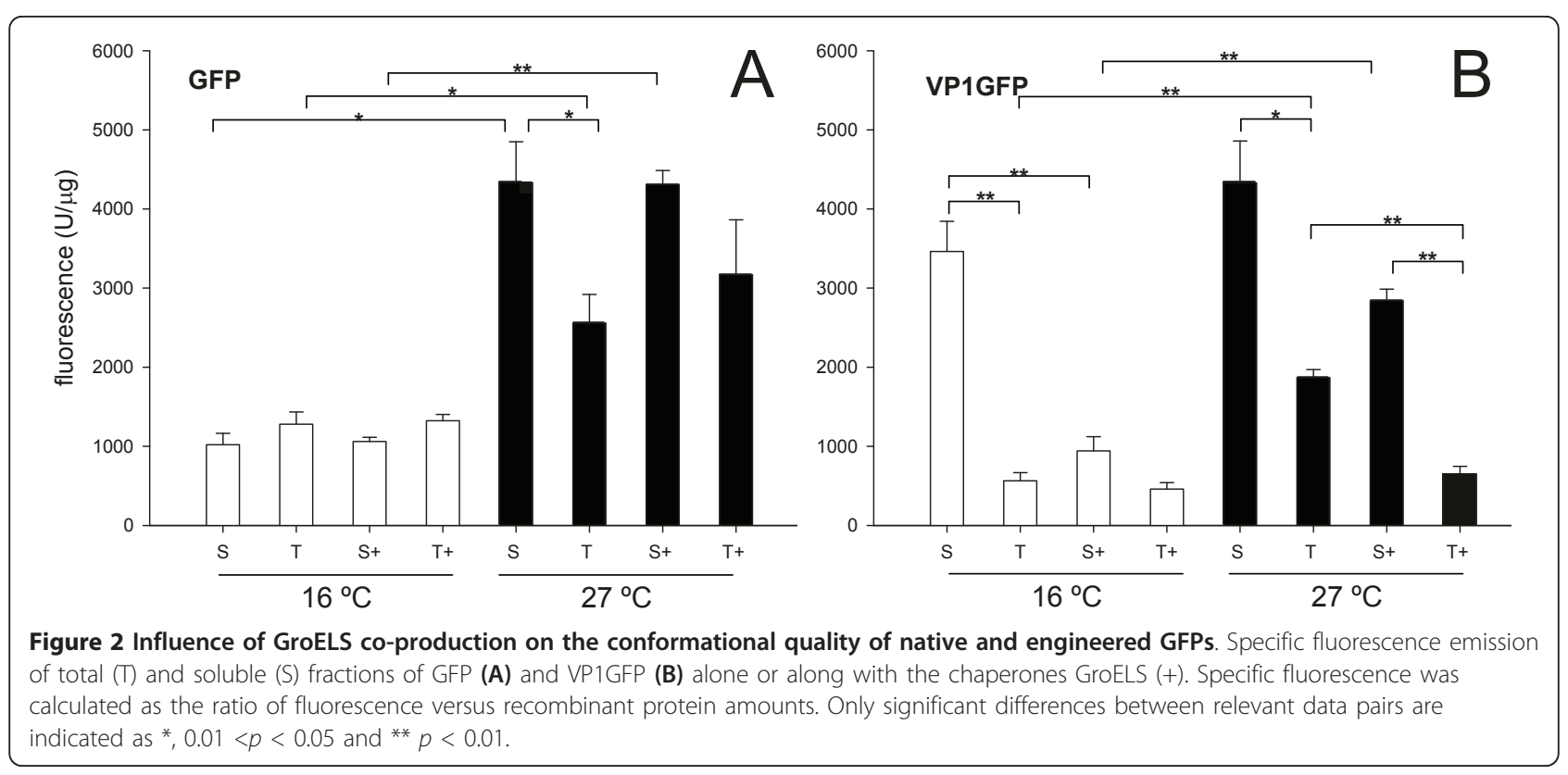


unaffected by the external supply of GroELS (Figure $3 \mathrm{~A})$. On the other hand, $50 \%$ of recombinant VP1LAC was found in the insoluble cell fraction irrespective of GroELS co-production (Figure 3B). No temperatureinduced aggregation was observed in any case. Again, no symptoms of proteolysis were manifest regarding any of the $\beta$-galactosidase versions (Figure 3 ), although a minor, non significant reduction of $\beta$-galactosidase yield observed at both $16^{\circ} \mathrm{C}$ and $27^{\circ} \mathrm{C}$ could be compatible with GroELS-mediated degradation (Figure 3A). In this line, and irrespective of the events supporting the lower yield, the enzymatic activity of non-fused $\beta$-galactosidase was concomitantly higher in presence of externally supplied GroELS (Figure 4A). Again, this trend was not statistically significant although the inverse coincidence between yield and specific activity of the protein was evident. In contrast, the yield and functional quality of the largest protein version VP1LAC were essentially regular and it was unaffected by the chaperone pair (Figures $3 \mathrm{~B}$ and $4 \mathrm{~B}$ ).

In conclusion, co-production of GroELS along with non-fused, full length GFP did not have any effect on protein yield, stability and quality at $16^{\circ} \mathrm{C}$ (Figure $1 \mathrm{~A}$ ), conditions under which this protein was fully soluble. At $27^{\circ} \mathrm{C}$, GFP partially aggregated, indicating thermal aggression and conformational effects even at this mild temperature. GroELS pair was not able to recover the solubility of the protein under these conditions (Figure $1 \mathrm{~A}$ ), and neither its functional quality expressed as specific fluorescence emission (Figure 2B). On the other hand, no signs of GFP or VP1GFP proteolysis associated to GroELS production were observed (Figure 1), although a slight reduction in the yield of $\beta$ - galactosidase was evidenced in presence of the recombinant chaperones (Figure 3), that might be compatible with the occurrence of degradation. Contrarily, GroELS dramatically enhanced the yield of VP1GFP (Figure 2), what could be in turn associated to a stabilizing effect of the chaperone pair on the chimerical protein. Concomitantly, GroELS reduced the fluorescence emission of both soluble and insoluble VP1GFP versions (Figure 2B).

\section{Discussion}

The examination of the solubility and conformational quality of non-fused and chimerical versions of two structurally different model proteins indicate that the GroELS chaperone pair does not modulate the folding of thermally-injured GFP, but instead that of the aggregation-prone version of this protein (VP1GFP), which size (around $50 \mathrm{kDa}$ ) should still permit its encapsulation by GroELS complexes [39]. This suggests a differential role of GroELS in thermal induced and intrinsic aggregation pathways of their substrates. Although there is not straightforward experimental data fully demonstrating this hypothesis, data presented in Figure 1B suggest a proteolytic stabilization of VP1GFP that enhances its yield. In agreement with previous observations [15], such an increase in the intracellular concentration of the chimerical protein reduces its conformational quality, in both soluble and insoluble cell fractions (Figure 2 ). This fact indicates that recombinant protein yield and quality are divergent features and supports the concept that both parameters cannot be simultaneously enhanced in E. coli [40], at least for aggregation-prone proteins. Such a divergence is also supported by the slight increase of $\beta$-galactosidase activity mediated by
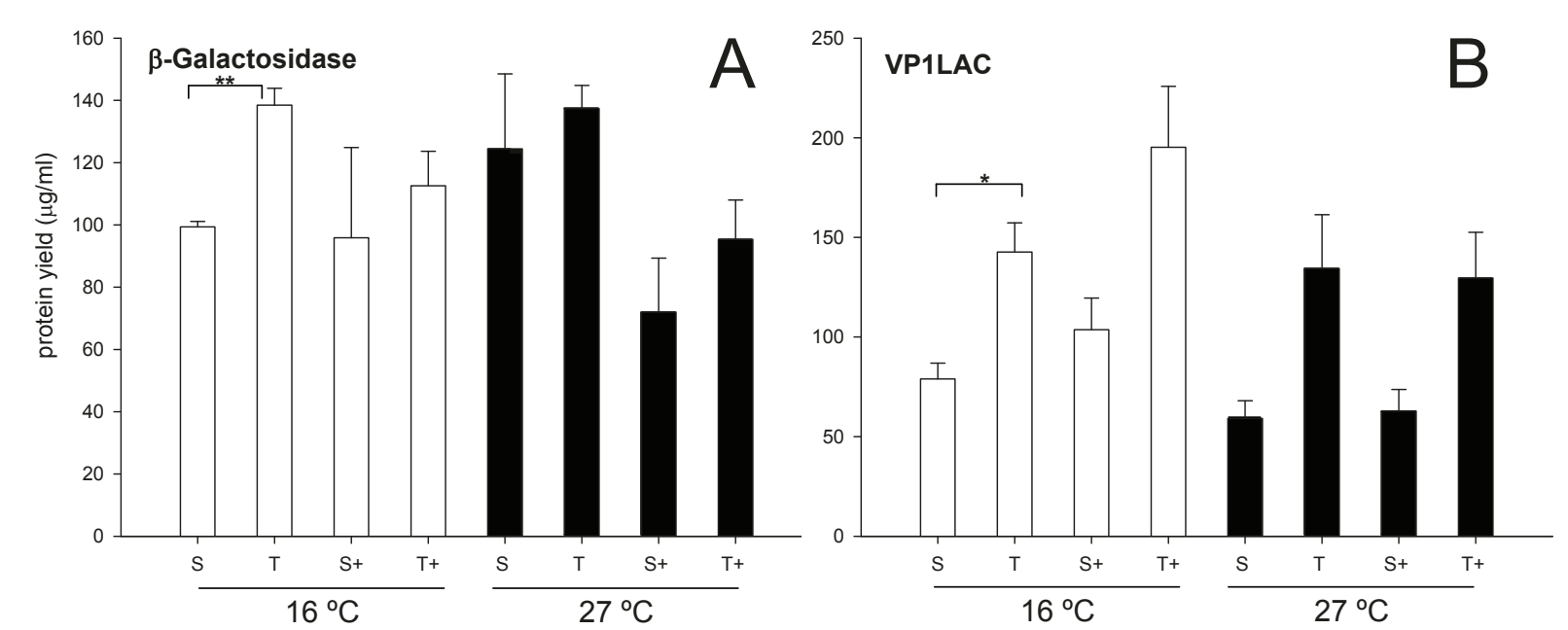

Figure 3 Influence of GroELS co-production on yield and solubility of native and engineered $\boldsymbol{\beta}$-galactosidases. Yield of total (T) and soluble (S) $\beta$-galactosidases (A) and VP1LAC (B) produced alone or along with the chaperones GroELS (+). Only significant differences between relevant data pairs are indicated as $*, 0.01<p<0.05$ and ${ }^{* *} p<0.01$. 

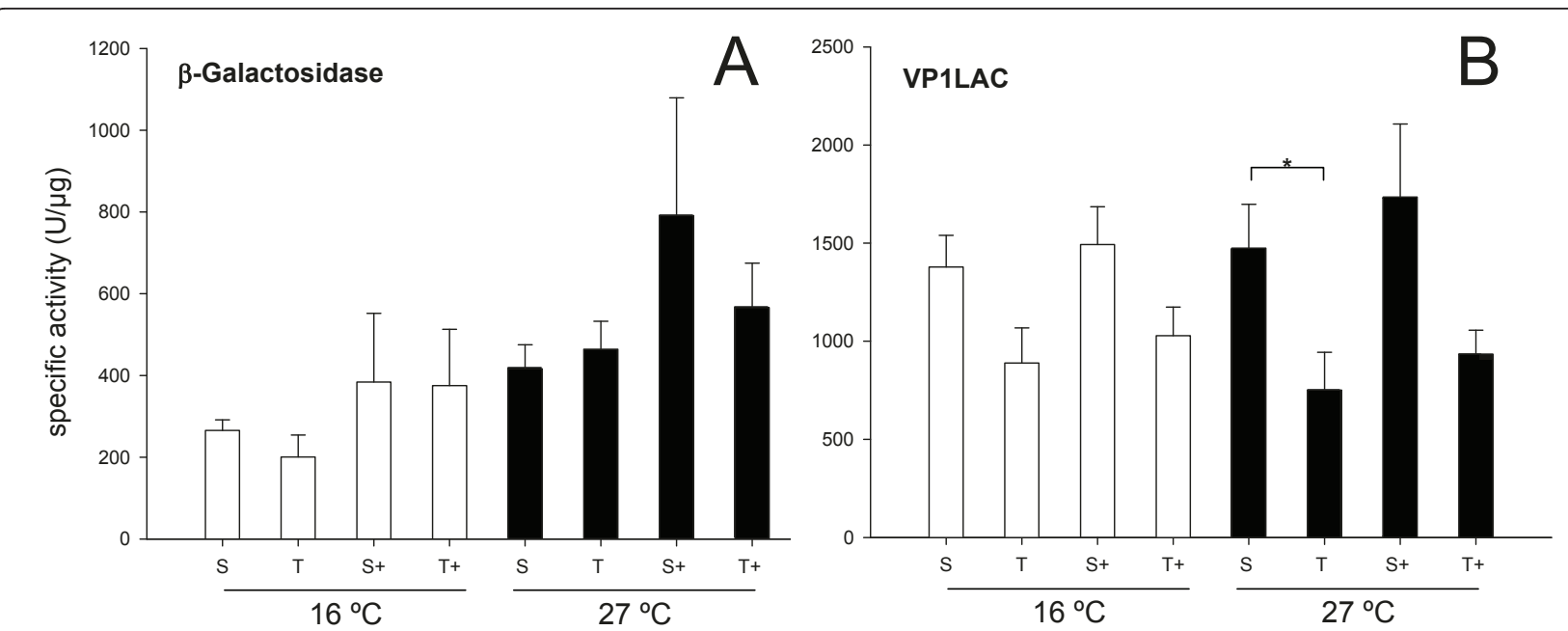

Figure 4 Influence of GroELS co-production on the conformational quality of native and engineered $\beta$-galactosidases. Specific activity of total (T) and soluble (S) $\beta$-galactosidases (A) and VP1LAC (B) produced alone or along with the chaperones GroELS (+). Only significant differences between relevant data pairs are indicated as ${ }^{*}, 0.01<p<0.05$ and ${ }^{* *} p<0.01$.

GroELS concomitant to the reduction of protein yield (Figures $3 \mathrm{~A}$ and $4 \mathrm{~A}$ ). Also, the parallel behaviour regarding functional activity of soluble and insoluble GFP versions is in the line of the "continuum-of-forms" model of recombinant protein production in bacteria [41], that claim for the extreme dynamism of protein aggregation-disaggregation [37] and that offers a mechanistic explanation about why insoluble protein species are not excluded from the cell's quality control [42]. GroELS was not able to positively reduce aggregation of VP1GFP (Figure 1B), a role that seems limited to DnaK and associated $\mathrm{AAA}^{+}$disaggregating proteins [43].

Finally, overproduction of GroELS shows extremely mild effects on the production of two versions of the large $\beta$-galactosidase protein, which cannot be encapsulated by GroEL rings. This is in agreement with previous observations of GroEL null effects on the folding of RNA polymerases [44] and other large proteins [10]. In our hands, GroEL tends to reduce the yield of $\beta$-galactosidase without affecting the partitioning between soluble and insoluble cell fractions, suggesting a negative role of this chaperone on protein stability, as shown before for a limited set of abnormal and native cellular proteins [45-48]. In this regard, it has been observed that GroEL interacts externally (without the cooperation of GroES) with proteins too large to be encapsulated [49]. The negative influence of GroELS on protein yield, although no statistically significant, is supported by the rise of the specific enzymatic activity in GroELS-producing cells.

In summary, we have not observed any positive effect on the yield, production and folding of thermally aggregated GFP but positive GroELS activities on the yield of an aggregation-prone version of GFP (VP1GFP).
Variations in the nominal solubility of these proteins (determined as soluble protein amounts over total protein) during overproduction of the chaperone pair seem to be irrelevant numerical alterations of these ratios derived from data scattering, as no solubilising effects of GroELS were in any case evidenced through a reduction of the absolute amounts of insoluble species. The increase of VP1GFP yield, especially dramatic at $16^{\circ} \mathrm{C}$, can be attributed to protein stabilization. Contrarily, GroELS co-production has mild (if any) effects on large proteins that cannot be encapsulated, on which, however, the chaperone pair tends to reduce their proteolytic stability.

\section{Methods}

Bacterial strain, plasmids and proteins

The E. coli strain (MC4100 (araD139 (argF-lac)U169 rpsL150relA1 flbB5301 deoC1 ptsF25 rbsR)) was used in all the experiments. The recombinant proteins were produced by expressing the encoding genes from the ampicillin-resistant pTrc99A-derivatives pTGFP (encoding GFP), pTVP1GFP (encoding VP1GFP), pTCO46 (encoding a pseudo-wild type $\beta$-galactosidase) and pTVP1LAC (encoding VP1LAC). No leader peptides were fused in any case so all the proteins remained in the cell's cytoplasm. More details about these constructs where provided elsewhere $[15,33,35]$. GroELS pair was supplied from the plasmid pBB541 $\left(\mathrm{Km}^{\mathrm{R}}\right)$, kindly provided by Prof B. Bukau.

\section{Culture and sampling conditions}

LB medium [50] with the corresponding plasmid-maintenance antibiotics (ampicilin at $100 \mu \mathrm{g} / \mathrm{ml}$ and 
kanamycin at $60 \mu \mathrm{g} / \mathrm{ml}$, when necessary) was used in all the experiments. Cells from overnight cultures were diluted at 1:50 in $120 \mathrm{ml}$ of fresh media and grown at either $16^{\circ} \mathrm{C}$ or $27^{\circ} \mathrm{C}$, within $500 \mathrm{ml}$ shake flasks, at 250 $\mathrm{rpm}$. Induction of gene expression (encoding both the models protein and the chaperone set) was triggered by the addition of $1 \mathrm{mM}$ IPTG at an $\mathrm{OD}_{550}=0.5$. Cultures were always done in triplicate to ensure statistic robustness.

\section{Sampling and protein analysis}

Samples of $15 \mathrm{ml}$ were taken when $\mathrm{OD}_{550}$ reached 23 , after the induction of gene expression and cells sedimented by low speed centrifugation at $6.000 \mathrm{~g}$ for $10 \mathrm{~min}$. Cells were disrupted by sonication as described [51] and soluble cell fraction recovered by centrifugation at $15.000 \mathrm{~g}$ for $15 \mathrm{~min}$. Total cell extracts and the separated soluble cell fraction were run in PAGE-electrophoresis as described [15] and protein bands identified by further Western blot analysis, using commercial anti-GFP and anti- $\beta$-galactosidase antibodies as described [35]. The amount of proteins was determined by Quantity One ${ }^{\circledR}$ software using dilutions of commercial GFP and $\beta$-galactosidase proteins as standards. Fluorescence emission and $\beta$-galactosidase enzymatic activity were determined by standard fluorimetry or enzymatic determination (Miller's method) respectively [35]. Significance of differences between relevant data pairs were evaluated by a Student's t-test.

\section{Acknowledgements \\ The authors appreciate the financial support to recombinant protein production and application through MICINN (BFU2010-17450, ACI2009-0919, EUI2008-03610-ERANET-IB08-007) and AGAUR (2009SGR-108). We also appreciate the support from The Biomedical Research Networking Center in Bioengineering, Biomaterials and Nanomedicine (CIBER-BBN, Spain), an initiative funded by the VI National R\&D\&i Plan 2008-2011, Iniciativa Ingenio 2010, Consolider Program, CIBER Actions and financed by the Instituto de Salud Carlos III with assistance from the European Regional Development Fund. We are indebted to the Protein Production Platform (CIBER-BBN) for helpful technical assistance and for protein production and purification services http://bbn.ciber-bbn.es/programas/plataformas/equipamiento. A. Villaverde has been granted with an ICREA ACADEMIA award (from ICREA, Catalonia, Spain).}

\section{Author details}

${ }^{1}$ Institut de Biotecnologia i de Biomedicina, Universitat Autònoma de Barcelona, Bellaterra, Barcelona, Spain. ${ }^{2}$ Department of Genetics and Microbiology, Universitat Autònoma de Barcelona, Bellaterra, Barcelona, Spain. ${ }^{3} \mathrm{CIBER}$ de Bioingeniería, Biomateriales y Nanomedicina (CIBER-BBN), Bellaterra, Barcelona, Spain.

\section{Authors' contributions}

GP, ERC, EGF and OC performed the experiments, processed data and prepared the graphic files. ERC, EGF and AV conceived and designed the experimental approach. AV coordinated the whole study and redacted and prepared the manuscript in its final form. GP, ERC, EGF have equally contributed to this work. All authors read and approved the final manuscript.

\section{Competing interests}

The authors declare that they have no competing interests.

Received: 5 September 2011 Accepted: 12 October 2011

Published: 12 October 2011

\section{References}

1. Ferrer-Miralles N, Domingo-Espin J, Corchero JL, Vazquez E, Villaverde A: Microbial factories for recombinant pharmaceuticals. Microb Cell Fact 2009, 8:17.

2. Baneyx F, Mujacic M: Recombinant protein folding and misfolding in Escherichia coli. Nat Biotechnol 2004, 22:1399-1408.

3. Sorensen HP, Mortensen KK: Advanced genetic strategies for recombinant protein expression in Escherichia coli. J Biotechnol 2005, 115:113-128.

4. Gasser B, Saloheimo M, Rinas U, Dragosits M, Rodriguez-Carmona E, Baumann $\mathrm{K}$, et al: Protein folding and conformational stress in microbial cells producing recombinant proteins: a host comparative overview. Microb Cell Fact 2008, 7:11.

5. Garcia-Fruitos E, Vazquez E, Gonzalez-Montalban N, Ferrer-Miralles N, Villaverde A: Analytical Approaches for Assessing Aggregation of Protein Biopharmaceuticals. Curr Pharm Biotechnol 2011.

6. Frokjaer S, Otzen DE: Protein drug stability: a formulation challenge. Nat Rev Drug Discov 2005, 4:298-306.

7. Sorensen HP, Mortensen KK: Soluble expression of recombinant proteins in the cytoplasm of Escherichia coli. Microb Cell Fact 2005, 4:1.

8. Bukau B, Weissman J, Horwich A: Molecular chaperones and protein quality control. Cell 2006, 125:443-451.

9. de Marco A: Protocol for preparing proteins with improved solubility by co-expressing with molecular chaperones in Escherichia coli. Nat Protoc 2007, 2:2632-2639.

10. Martinez-Alonso M, Garcia-Fruitos E, Ferrer-Miralles N, Rinas U, Villaverde A: Side effects of chaperone gene co-expression in recombinant protein production. Microb Cell Fact 2010, 9:64.

11. Martinez-Alonso M, Gonzalez-Montalban N, Garcia-Fruitos E, Villaverde A: Learning about protein solubility from bacterial inclusion bodies. Microb Cell Fact 2009, 8:4.

12. de Marco A, Deuerling E, Mogk A, Tomoyasu T, Bukau B: Chaperone-based procedure to increase yields of soluble recombinant proteins produced in E. coli. BMC Biotechnol 2007, 7:32.

13. Martinez-Alonso M, Toledo-Rubio V, Noad R, Unzueta U, Ferrer-Miralles N, Roy $\mathrm{P}$, et al: Re-hosting bacterial chaperones for high-quality protein production. Appl Environ Microbiol 2009.

14. Martinez-Alonso M, Vera A, Villaverde A: Role of the chaperone DnaK in protein solubility and conformational quality in inclusion body-forming Escherichia coli cells. FEMS Microbiol Lett 2007, 273:187-195.

15. Garcia-Fruitos E, Martinez-Alonso M, Gonzalez-Montalban N, Valli M, Mattanovich D, Villaverde A: Divergent Genetic Control of Protein Solubility and Conformational Quality in Escherichia coli. J Mol Biol 2007, 374:195-205

16. Weibezahn J, Schlieker C, Tessarz P, Mogk A, Bukau B: Novel insights into the mechanism of chaperone-assisted protein disaggregation. Biol Chem 2005, 386:739-744.

17. Rodriguez F, rsene-Ploetze F, Rist W, Rudiger S, Schneider-Mergener J, Mayer MP, et al: Molecular basis for regulation of the heat shock transcription factor sigma32 by the DnaK and DnaJ chaperones. Mol Cell 2008, 32:347-358.

18. García-Fruitós E, Rodríguez-Carmona E, Díez-Gil C, Ferraz RM, Vázquez E, Corchero $\mathrm{L}$, et al: Surface Cell Growth Engineering Assisted by a Novel Bacterial Nanomaterial. Advanced Materials 2009, 21:4249-4253.

19. Ziemienowicz A, Skowyra D, Zeilstra-Ryalls J, Fayet O, Georgopoulos C, Zylicz M: Both the Escherichia coli chaperone systems, GroEL/GroES and DnaK/DnaJ/GrpE, can reactivate heat-treated RNA polymerase. Different mechanisms for the same activity. J Biol Chem 1993, 268:25425-25431.

20. Carrio MM, Villaverde A: Role of molecular chaperones in inclusion body formation. FEBS Lett 2003, 537:215-221.

21. Makino $Y$, Taguchi $H$, Yoshida M: Truncated GroEL monomer has the ability to promote folding of rhodanese without GroES and ATP. FEBS Lett 1993, 336:363-367.

22. Kolaj O, Spada S, Robin S, Wall JG: Use of folding modulators to improve heterologous protein production in Escherichia coli. Microb Cell Fact 2009, $8: 9$. 
23. Gragerov A, Nudler E, Komissarova N, Gaitanaris GA, Gottesman ME, Nikiforov V: Cooperation of GroEL/GroES and DnaK/DnaJ heat shock proteins in preventing protein misfolding in Escherichia coli. Proc Natl Acad Sci USA 1992, 89:10341-10344.

24. Langer T, Lu C, Echols H, Flanagan J, Hayer MK, Hartl FU: Successive action of DnaK, DnaJ and GroEL along the pathway of chaperone-mediated protein folding. Nature 1992, 356:683-689.

25. Buchberger A, Schroder H, Hesterkamp T, Schonfeld HJ, Bukau B: Substrate shuttling between the DnaK and GroEL systems indicates a chaperone network promoting protein folding. J Mol Biol 1996, 261:328-333.

26. Ewalt $\mathrm{KL}$, Hendrick JP, Houry WA, Hartl FU: In vivo observation of polypeptide flux through the bacterial chaperonin system. Cell 1997, 90:491-500.

27. Hwang DJ, Tumer NE, Wilson TM: Chaperone protein GrpE and the GroEL/GroES complex promote the correct folding of tobacco mosaic virus coat protein for ribonucleocapsid assembly in vivo. Arch Virol 1998, 143:2203-2214.

28. Nakonechny WS, Teschke CM: GroEL and GroES control of substrate flux in the in vivo folding pathway of phage P22 coat protein. J Biol Chem 1998, 273:27236-27244.

29. Rinas U, Hoffmann F, Betiku E, Estape D, Marten S: Inclusion body anatomy and functioning of chaperone-mediated in vivo inclusion body disassembly during high-level recombinant protein production in Escherichia coli. J Biotechnol 2007, 127:244-257.

30. Pletneva NV, Pletnev VZ, Lukyanov KA, Gurskaya NG, Goryacheva EA, Martynov VI, et al: Structural evidence for a dehydrated intermediate in green fluorescent protein chromophore biosynthesis. J Biol Chem 2010, 285:15978-15984.

31. Jacobson RH, Zhang XJ, DuBose RF, Matthews BW: Three-dimensional structure of beta-galactosidase from E. coli. Nature 1994, 369:761-766.

32. de Groot NS, Ventura S: Protein activity in bacterial inclusion bodies correlates with predicted aggregation rates. J Biotechnol 2006, 125:110-113.

33. Corchero JL, Viaplana E, Benito A, Villaverde A: The position of the heterologous domain can influence the solubility and proteolysis of beta-galactosidase fusion proteins in E. coli. J Biotechnol 1996, 48:191-200.

34. Waldo GS, Standish BM, Berendzen J, Terwilliger TC: Rapid protein-folding assay using green fluorescent protein. Nat Biotechnol 1999, 17:691-695.

35. Garcia-Fruitos E, Gonzalez-Montalban N, Morell M, Vera A, Ferraz RM, Aris A, et al: Aggregation as bacterial inclusion bodies does not imply inactivation of enzymes and fluorescent proteins. Microb Cell Fact 2005, 4:27.

36. Carrio MM, Villaverde A: Localization of chaperones DnaK and GroEL in bacterial inclusion bodies. J Bacteriol 2005, 187:3599-3601.

37. Carrio MM, Villaverde A: Construction and deconstruction of bacterial inclusion bodies. J Biotechnol 2002, 96:3-12.

38. Petersson L, Carrio MM, Vera A, Villaverde A: The impact of dnaK overexpression on recombinant protein solubility results from antagonistic effects on the control of protein quality. Biotechnol Lett 2004, 26:595-601.

39. Sakikawa C, Taguchi H, Makino Y, Yoshida M: On the maximum size of proteins to stay and fold in the cavity of GroEL underneath GroES. J Biol Chem 1999, 274:21251-21256

40. Martinez-Alonso M, Garcia-Fruitos E, Villaverde A: Yield, solubility and conformational quality of soluble proteins are not simultaneously favored in recombinant Escherichia coli. Biotechnol Bioeng 2008, 101:1353-1358.

41. Ventura S, Villaverde A: Protein quality in bacterial inclusion bodies. Trends Biotechnol 2006, 24:179-185.

42. Gonzalez-Montalban N, Garcia-Fruitos E, Villaverde A: Recombinant protein solubility-does more mean better? Nat Biotechnol 2007, 25:718-720.

43. Weibezahn J, Bukau B, Mogk A: Unscrambling an egg: protein disaggregation by AAA+ proteins. Microb Cell Fact 2004, 3:1

44. Han KG, Lee SS, Kang C: Soluble expression of cloned phage K11 RNA polymerase gene in Escherichia coli at a low temperature. Protein Expr Purif 1999, 16:103-108.

45. Kandror O, Sherman M, Goldberg A: Rapid degradation of an abnormal protein in Escherichia coli proceeds through repeated cycles of association with GroEL. J Biol Chem 1999, 274:37743-37749.

46. Zahrl D, Wagner A, Tscherner M, Koraimann G: GroEL plays a central role in stress-induced negative regulation of bacterial conjugation by promoting proteolytic degradation of the activator protein TraJ. J Bacteriol 2007, 189:5885-5894.

47. Kandror O, Sherman M, Rhode M, Goldberg AL: Trigger factor is involved in GroEL-dependent protein degradation in Escherichia coli and promotes binding of GroEL to unfolded proteins. EMBO J 1995, 14:6021-6027.

48. Kandror O, Busconi L, Sherman M, Goldberg AL: Rapid degradation of an abnormal protein in Escherichia coli involves the chaperones GroEL and GroES. J Biol Chem 1994, 269:23575-23582.

49. Chaudhuri TK, Farr GW, Fenton WA, Rospert S, Horwich AL: GroEL/GroESmediated folding of a protein too large to be encapsulated. Cell 2001, 107:235-246

50. Sambrook J, Fritsch E, Maniatis T: Molecular Cloning, A Laboratory Manual Cold Spring Harbor, NY: Cold Spring Harbor Laboratory Press; 1989.

51. Feliu JX, Cubarsi R, Villaverde A: Optimized release of recombinant proteins by ultrasonication of E. coli cells. Biotechnol Bioeng 1998, 58:536-540.

doi:10.1186/1475-2859-10-79

Cite this article as: Platas et al: Co-production of GroELS discriminates between intrinsic and thermally-induced recombinant protein aggregation during substrate quality control. Microbial Cell Factories 2011 10:79.

\section{Submit your next manuscript to BioMed Central and take full advantage of:}

- Convenient online submission

- Thorough peer review

- No space constraints or color figure charges

- Immediate publication on acceptance

- Inclusion in PubMed, CAS, Scopus and Google Scholar

- Research which is freely available for redistribution

Submit your manuscript at www.biomedcentral.com/submit
C Biomed Central 